Article

\title{
Typology of Options for Metal Recycling: Australia's Perspective
}

\author{
Artem Golev * and Glen D. Corder \\ Received: 31 July 2015; Accepted: 22 December 2015; Published: 30 December 2015 \\ Academic Editor: Damien Giurco \\ Centre for Social Responsibility in Mining, Sustainable Minerals Institute, The University of Queensland, \\ St Lucia, QLD 4072, Australia; g.corder@smi.uq.edu.au \\ * Correspondence: a.golev@uq.edu.au; Tel.: +61-7-3346-4136; Fax: +61-7-3346-4045
}

\begin{abstract}
While Australia has traditionally relied on obtaining metals from primary sources (namely mined natural resources), there is significant potential to recover metals from end-of-life-products and industrial waste. Although any metals recycling value chain requires a feasible technology at its core, many other non-technical factors are key links in the chain, which can compromise the overall viability to recycle a commodity and/or product. The "Wealth from Waste" Cluster project funded by the Commonwealth Scientific Industrial Research Organisation (CSIRO) Flagship Collaboration Fund and partner universities is focusing on identifying viable options to "mine" metals contained in discarded urban infrastructure, manufactured products and consumer goods. A key aspect of this research is to understand the critical non-technical barriers and system opportunities to enhance rates of metals recycling in Australia. Work to date has estimated the mass and current worth of metals in above ground resources. Using these outcomes as a basis, a typology for different options for (metal) reuse and recycling has been developed to classify the common features, which is presented in this article. In addition, the authors investigate the barriers and enablers in the recycling value chain, and propose a set of requirements for a feasible pathway to close the material loop for metals in Australia.
\end{abstract}

Keywords: metal flows; recycling; supply chain; circular economy; Australia

\section{Introduction}

Australia remains a strong net exporter of a wide range of mineral commodities, and especially metallic minerals. The multibillion revenue generated by the mining sector [1] allowed the country's economy to stably grow over the last few decades. This is illustrated by recent export revenue of metals and metal concentrates (58\% in 2012/13, worth AUD101.2 billion), energy resources such as coal, natural gas and uranium (38\%, worth AUD67.4 billion) and other minerals exports (worth AUD7.3 billion) totaling over AUD175 billion [2]. At the same time, being among the most developed countries in the world and allowing for higher level of resources consumption, Australia generates a significant amount of waste materials per capita [2], which could provide the economy with the secondary resources and partially offset the need for virgin raw materials.

The amount of metals in the extracted and exported mineral concentrates in the last decade was about 30 times higher than Australia's needs in metals. From our research in the "Wealth from Waste" Cluster project we ascertained that that net export of metal concentrates (in 100\% metal content) grew from about $114 \mathrm{Mt}$ in 2002 to $289 \mathrm{Mt}$ in 2011, while the domestic consumption of metals accounted for $8.8 \mathrm{Mt}$ and 12.3 Mt of metals in the corresponding years [3]. While not denying the dependence of Australia on mining and minerals industry revenue for economic growth, we believe that a better understanding of metal cycles in the economy can provide a pathway to Australia's leading role in resources stewardship, including accounting and highlighting the need for both primary and secondary 
resources in the economy, and comprehensively targeting the associated economic, environmental, and community related impacts from resources supply. Moreover, Australia is well placed given its expertise in developing primary resources from mineral deposits to help develop innovative and more effective processes for recovering metals from secondary resources, such as end-of-life products and industrial waste.

The current level of waste metal generation in Australia equals approximately $50 \%$ of the country's metals consumption [2]. In comparison with primary smelter production, the annually generated scrap covers more than $100 \%$ of iron production, and from $10 \%$ to $30 \%$ of aluminium, copper and lead smelting [3]. The recent statistics on metal recycling, however, indicate that the recycled content in metal production in Australia remains relatively low, ranging from $0 \%-5 \%$ for major non-ferrous metals to about $25 \%-30 \%$ for crude steel [3].

The overall aim of this article is to demonstrate that there is a need for a more systematic categorization of the possible recycling value chains which enable a sufficient level of understanding of the barriers and enablers to access a larger alternative source of metals through the processes of "urban mining" which will result in higher levels of metals recycling in the Australian context.

To achieve this aim, the article presents a guiding framework that comprises a new classification of metals recycling for end-of-life (EoL) products and an associated typology of different options to help select the feasible pathways for (metal) reuse and recycling of the more problematic waste streams to increase the level of metals circularity in the Australian economy.

\section{Metal Inputs and Outputs in the Economy}

Unlike metals and minerals from primary sources, there is limited information on the type of metal and metal contained products consumed and scrapped in Australia. A detailed investigation for a specific metal or commodity cycle in the economy is a very intensive and complex process. However, it is evident that the majority of metals are consumed for buildings, infrastructure, machinery, and vehicles, and locked in there for an extended period of time. The lack of information and data of metals in waste products presents challenges in producing an overall picture of the metal usage in the Australian economy. Based on a combination of data analysis techniques presented elsewhere [4], the overall amount of consumed metals in Australia in 2012/13 was estimated to be 12 million tonnes or about $520 \mathrm{~kg}$ per person; the amount of generated scrap, waste metal and other losses is seven million tonnes or about $300 \mathrm{~kg}$ per person (Figure 1).

\begin{tabular}{|c|c|c|}
\hline Input (consumption) & $\underline{\text { In-use stocks }}$ & Output (scrap and losses) \\
\hline$\underline{12 \mathrm{Mt}}$ & $\underline{300 \mathrm{Mt}}$ & $\underline{7 \mathbf{M t}}$ \\
\hline Buildings and & Buildings and & Buildings and \\
\hline infrastructure [45\%] & infrastructure $[50-70 \%]$ & infrastructure [35\%] \\
\hline Vehicles [25\%] & Vehicles [15-25\%] & Vehicles $[30 \%]$ \\
\hline Machinery, consumer & Machinery, consumer & Machinery, consumer \\
\hline products, other [30\%] & products, other [15-25\%] & products, other [35\%] \\
\hline
\end{tabular}

Figure 1. Estimation of metal inputs and outputs in the Australian economy by major sectors (2012/13). Source: [4].

The official classification for waste materials in Australia is based on the waste collection system and includes three major groups: municipal solid waste (MSW), commercial and industrial (C \& I) waste, and construction and demolition (C \& D) waste [5]. There are some variations in the reporting system used by municipalities in different states across the country, as well as there are different reporting requirements for waste processors and metal recyclers.

From our research to date we consider the recovery of metal from C \& D waste, C \& I waste, and end-of-life (EoL) vehicles to be operating in well-established businesses. On the other hand, the 
collection and recycling of EoL consumer products is a relatively new area. The consumer products, including different electronic devices, are becoming an important category for metal reuse and recycling due to their high annual growth rates, relatively short life cycle, and significant metal content, including the presence of precious and critical metals [6]. For instance, in 2014 Australia had the highest electronic waste, or e-waste, generation in the Oceania region both in absolute terms $(0.47 \mathrm{Mt})$ and per capita (20 kg) [7].

A significant part of the data used for investigating metal flows in the economy still relies on expert assumptions. While the official reported metal collection rates in Australia exceed 90\% [8], we believe from our research analysis that the real metal recycling rates (EoL-RR) are below 70\% [4]. This is due to a certain metal loss in obsolete (degraded) stocks and unaccounted losses during the waste metal collection and processing. Therefore, there are still opportunities for enhancing the collection and recovery, including preventing metal losses at the disposal and stimulating secondary metal production within the country versus importing scrap overseas, including metal recovery from consumer products. In addition, it is worth highlighting that there is significant metals value in EoL products. A recent report stated the gold content from e-waste worldwide in 2014 was roughly 300 tonnes, which represents 11\% of the global gold production from mines in 2013 (2770 tonnes) [7]. The same report also estimated that the value of a range of key metals (iron/steel, copper, aluminium, gold, silver, palladium) in e-waste worldwide in 2014 was about 36 billion Euros (AUD53 billion) [7].

\section{Depicting the Value Chain for Recycling}

The concept of the circular economy is based on the model where the EoL products form the basis for continuous resource value chains, ranging from repair and reuse to remanufacturing and recycling [9]. The product design for reuse and recycling becomes an imperative to enable the circulation of resources. The idea of circular use of resources, however, is applicable at a global level rather than a separate region or country level. When developing national policy and targets for reuse and recycling, it is important to recognise the boundaries for recoverable resources circulation within and outside the domestic borders.

In general terms, the recycling of metal starts with EoL products collection, followed by product disassembly and basic separation. The metal containing parts have to undergo several stages of transformation (such as crushing, separation, leaching, smelting, refining), including waste management for losses and/or by-products. The final output can be refined metal or alloy, or fabricated metal products. Several value chain options can occur in relation to recycling of collected EoL products as shown in Figure 2:

1. direct export (a);

2. separated into metal scrap and other materials, and exported (b);

3. metal scrap can be smelted into refined metal products, and exported (c);

4. recovered metal is used for product fabrication, for export and/or domestic consumption (d).

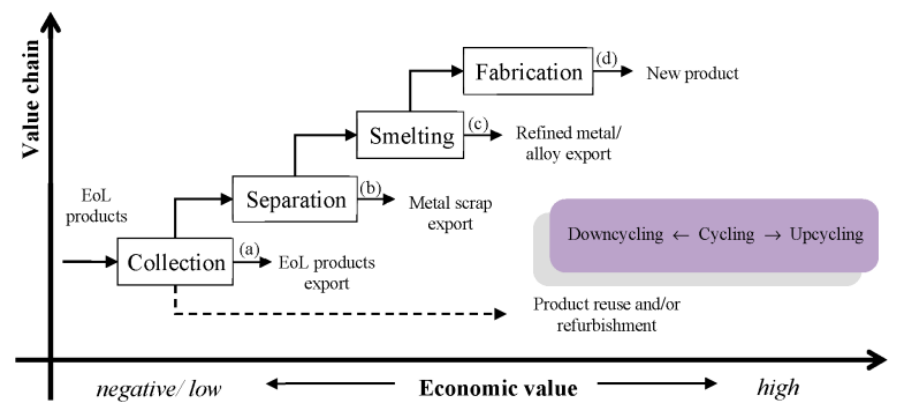

Figure 2. Value chain for EoL products recycling. 
Figure 2 presents the authors' schematic interpretation of the economic value for EoL products recycling along the recycling value chain. It shows that for every subsequent step in the value chain the economic value of recovered materials becomes higher, contributing to gross domestic product in the country. Establishing collection systems for EoL products is the first element in the recycling value chain. The economic value derived from exporting waste products (for material recovery overseas) is usually very low if not negative, excluding savings on landfill levies and/or higher processing costs in the country of origin. The separation and recovery of materials from EoL products creates new jobs and revenue within the country $[6,10,11]$. Depending on the depth of processing and final output, the economic value can vary from relatively low (e.g., metal scrap export) to very high (e.g., fabrication of new products). The preferred or best route in Figure 2 for any EoL product will depend on the associated costs for each of the options in that region and/or the country.

Only the recovery of materials into new products (maintaining the original quality of recycled materials) can be characterised as a true circular use of resources. While this may be desirable to occur within one country, it is mainly achievable at the global scale due to the fact that many products are imported from overseas, and not all recovered materials/metals may be needed for domestic production. In every case, there should be a distinction for the appropriate supply loop for materials recovered from EoL products [12].

The recovered materials (and/or new products) at the separation, smelting and fabrication stages can also be characterised with lower, similar or higher quality and value, if compared to the original input materials in the product. These are called downcycling, cycling, and upcycling respectively in Figure 2. Common examples of downcycling include the use of mixed streams of high-purity aluminium alloys to create less pure casting alloys, and the loss/waste of alloying elements in the processing of mixed streams of stainless steel scrap [13]. Downcycling can also be viewed through the cascading theory, explaining the gradual decrease in resource quality over time after different reuse and recycling applications before final disposal and-or dissipation $[14,15]$. Many examples can be found for metal recycling (cycling) where the recovered metal has similar value and/or aimed for the same application, e.g., aluminium cans recycling. The examples for metal upcycling, however, are relatively rare, especially considering that any new application (with upcycled metal) has to allow/maintain the same quality (value) of resources for the next round of recycling. Nevertheless, there are strong economic and environmental benefits for promoting the cyclical use of resources via cycling (also referred to as high-grade recycling) and upcycling versus downcycling, but this distinction is rarely highlighted in the regulation and underrepresented in the academic literature.

\section{Classifying Options for Reuse and Recycling}

As mentioned in the Introduction, Australia has a wealth of natural resources as well as generating a significant amount of waste materials per capita. Historically, this abundance of natural resources has contributed to Australia being less concerned about recycling compared with other countries such as those in the European Union or Japan. Most of waste reuse initiatives in Australia over the last 20 years were primarily focusing on industrial (pre-consumer) waste [16].

At an international level, initiatives related to the circular economy and metals recycling are being advocated through the World Economic Forum [12] and through the United National Environment Programme [6]. Circular economy approaches, such as industrial ecology or industrial symbiosis, have been developed and are operating in China, through its Eco-industrial Park (EIP) network; in the UK, through the UK's National Industrial Symbiosis Programme; and in Europe more broadly, through its Resource Efficiency Flagship Initiative [16]. In addition, there are several research initiatives, such as the Center for Resource Recovery and Recycling (a multi-university initiative-Worcester Polytechnic Institute, Colorado School of Mines, and KU Leuven) and the Critical Minerals Institute in the U.S. Department of Energy, focusing on materials efficiency and recycling [2]. It is beyond the scope of this article to review the different approaches and issues encountered in other countries related to recycling and the related move towards circular economy thinking. Many of the issues regarding 
recycling are dependent on contextual circumstances and environments, such as geography, population density, social norms, infrastructure systems, regulations, etc., within the country or region in question. For this reason in this article, we have focused our efforts on identifying the distinctive features and characteristics pertinent to Australia for metals recycling. While we recognize that other parts of the world are more advanced in their approaches to metals recycling, there are still significant limitations and potential opportunities for metals recycling that have been brought about by the increasing complex nature of products that contain metals, particularly electrical and electronic equipment [5]. The approach presented in article is a new attempt to identify the feasible pathways to increase metals recycling of complex and problematic EoL products.

The collection system for waste metal in Australia can be characterised as being well-established [10], although a significant part of metal scrap is still present in the mixed municipal waste stream (domestic general waste bins) and ends up at landfills [8]. The opportunities for improvement exist at different stages in the recycling supply chain [4], but achieving higher levels of domestic recycling for already collected materials could deliver the most immediate and tangible benefits. However, a key question remains: how to innovate the recycling sector and benefit the economy through cyclical use of resources?

The existing practices and opportunities for material recovery from EoL products depend on the complexity of the products as well as the scale of processing operations. Some consumer products are relatively simple in terms of metal and other material mix; the conventional recycling operations for these products include shredding, magnetic separation and eddy current (e.g., fridges, washing machines) [6,17]. However, many electronic wastes (e.g., EoL computers, TVs, and mobile phones) are very complex often containing high concentrations of precious and rare metals; the recovery of the latter requires a separate advanced processing through pyro- and/or hydrometallurgical operations [17]. With insufficient scale, feasible options for recycling are significantly limited.

An overview of the existing recycling practices in Australia and worldwide through the workshops and industry contacts, as a part of the Wealth from Waste Cluster work [18,19], has allowed us to classify and map main strategies for metal recycling from EoL products in Figure 3. It is based on two main paramaters-scale and EoL product complexity; both of them are used as relative characteristics defining economic feasibility for metal recovery rather than absolute weight based figures. It should also be noted that it is rather challenging to make a direct comparison between Figures 1 and 3. It is obvious that a major part of metal flows associated with EoL products (perhaps more than $70 \%$ ) goes through conventional recycling (sector \#1 in Figure 3). This includes most of metal scrap arising from construction and demolition waste, EoL vehicles and machinery, and some large EoL consumer products. Nevertheless, the remaining part which is difficult to quantify on a product-by-product by basis due to the lack of available data in the Australian context, still represents an area of great importance to improve metal recycling rates, especially that part associated with waste electronic products.

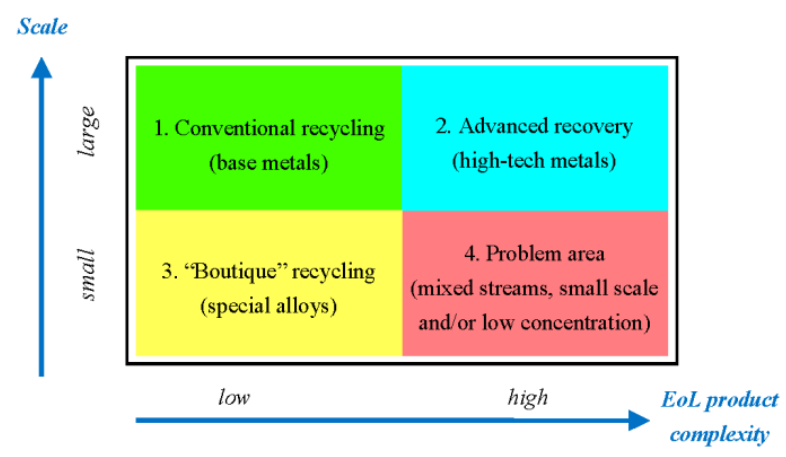

Figure 3. Main strategies for metal recycling from EoL products depending on scale, product complexity, and metal mix. 
The basis of diagram in Figure 3 is as follows:

- Sector \#1 represents collection and recycling of bulk waste metal streams and metal contained commodities, this type of recycling is a well established area in most countries.

- In contrast, the advanced recovery of high-tech and precious metals from EoL products in Sector \#2, including from waste electric and electronic equipment (WEEE), is usually concentrated in a few locations in the world. The types and value of WEEE vary greatly, and in many cases additional finanical support is required to collect and recycle these products. In Australia, the National Television and Computer Recycling Scheme partly covers the collection and separation costs for old TVs and computers. However, the collected WEEE are mainly shipped to large e-waste processing plants elsewhere, such as SIMS metal e-waste recycling facility in Singapore, and the Umicore plant in Europe [17].

- Recycling of special alloys in Sector \#3 is an example of a niche ("boutique") strategy. While the volumes can be rather small, the value of these alloys make it feasible to track and recover them from EoL products. Examples of this strategy in Australia include the recovery/remanufacturing of mining equipment parts made of stainless steel.

- Sector \#4 represents problem EoL products, and is the sector that is relevant to many EoL consumer products in Australia. With a lack of domestic recycling opportunities, the transitional strategies include temporary accumulation (in a personal garage, or centralized stockpile), export to third countries (where there is a scale of operations), collection and recycling under additional public costs and/or stewardship programs. In many cases, however, the landfill option still can be tolerated. It is this sector that is the key focus of the remainder of this article.

EoL products that fall into Sector \#4 suffer from several common characteristics. Often there is temporary accumulation of these waste products (including for future recovery), and despite being acknowledged in practice, they are not yet a part of a systematic government environmental policy or circular economy thinking. Furthermore, the strong desire on short-term financial benefits is a likely key reason for preventing wider acceptance of (valuable) waste accumulation and storage, as potential future "anthropogenic resource deposits".

There are potential preventive measures to mitigate the loss of resources with EoL products disposal such as:

- identifying and encouraging different reuse options;

- enabling disassembly for parts;

- designing and creating preference amongst consumers for products with longer life cycles;

- $\quad$ as well as developing and promoting new innovative solutions for recycling.

The schematic representation of the value chain for EoL products recycling in Figure 2 highlights that greater economic value is generated if EoL products can be collected and recycled through as many steps as possible provided the associated costs are manageable. The aim of the developed typology of options presented in Table 1 is to determine the potential for progressing along the value chain for recycling and re-use of an EoL product, and if there are points of influence that would enable this progression to occur. Even though this typology could be used for any of the metal recycling categorizations in Figure 3, its key aim is to help with identifying opportunities for problematic EoL products (Sector \#4). Depending on the product characteristics, collection system and reuse/processing route, not all options in Table 1 (and Figure 2) will be applicable and/or feasible for each EoL products. 
Table 1. Typology of options for reuse and recycling.

\begin{tabular}{|c|c|c|}
\hline Criteria & Options & Point(s) of Influence \\
\hline Re-use and recycling route & $\begin{array}{ll}\text { - } & \text { Reuse, repair, refurbishment } \\
\text { - } & \text { Disassembly for parts } \\
\text { - } & \text { Disassembly for material streams } \\
\text { - } & \text { Bulk recycling }\end{array}$ & $\begin{array}{l}\text { Product design, recycling } \\
\text { technology }\end{array}$ \\
\hline Resource recovery approach & $\begin{array}{l}\text { - } \quad \text { Product centric } \\
\text { - }\end{array}$ & $\begin{array}{l}\text { Product design, recycling } \\
\text { technology }\end{array}$ \\
\hline Reuse channels & $\begin{array}{ll}\text { - } & \text { Formal/regulated } \\
\text { - } & \text { Informal }\end{array}$ & $\begin{array}{l}\text { Regulation, business model, } \\
\text { public education }\end{array}$ \\
\hline Regulatory regime for recycling & $\begin{array}{ll}\text { - } & \text { Voluntary } \\
\text { - } & \text { Co-regulation } \\
\text { - } & \text { Regulation }\end{array}$ & Regulation, stewardship programs \\
\hline $\begin{array}{l}\text { Infrastructure and collection } \\
\text { system }\end{array}$ & $\begin{array}{ll}\text { - } & \text { Centralised collection } \\
\text { - } & \text { Special outlets for collection } \\
\text { - } & \text { Take-back schemes }\end{array}$ & Regulation, stewardship programs \\
\hline $\begin{array}{l}\text { Typical consumer behaviour for } \\
\text { EoL product }\end{array}$ & $\begin{array}{ll}\text { - } & \text { No interest in reuse and recycling (disposal) } \\
\text { - } & \text { Giving away (for reuse) } \\
\text { - } & \text { Self-delived recycling (e.g., kerbside collection) } \\
\text { - } & \text { Long-term storage of obsolete devices }\end{array}$ & Public education, regulation \\
\hline $\begin{array}{l}\text { Collection and recycling costs } \\
\text { covered by }\end{array}$ & $\begin{array}{ll}\text { - } & \text { Producer } \\
\text { - } & \text { Consumer } \\
\text { - } & \text { Recycling company } \\
\text { - } & \text { Government }\end{array}$ & $\begin{array}{l}\text { Regulation, stewardship } \\
\text { programs, public education }\end{array}$ \\
\hline Relative recovery value & $\begin{array}{ll}\text { - } & \text { Negative } \\
\text { - } & \text { Low to zero } \\
\text { - } & \text { Medium } \\
\text { High }\end{array}$ & $\begin{array}{l}\text { Product design, recycling } \\
\text { technology }\end{array}$ \\
\hline
\end{tabular}

The most recent efforts in managing problematic waste streams in Australia under the Product Stewardship Act 2011, such as EoL household batteries, mobile phones, and TVs and computers can illustrate the developed approach in this article. For example, they highlight the key role of co-regulatory agreements and stewardship programs for establishing and funding the collection of EoL electronic products $[20,21]$. A further progression along the recycling supply chain is however still hindered by a lack of scale for establishing the full recovery operations in the country.

The presented typology (Table 1) can be used to both describe the existing situation in recycling of a specific EoL product stream, and to analyse the alternatives. The development of alternatives includes analysing of different barriers and enablers affecting higher reuse, collection and recycling rates within the value chain (refer to Figure 2), including:

1. availability and awareness of reuse channels;

2. brand recognition for product reuse and disassembly;

3. availability and affordability of collection and recycling infrastructure;

4. available solutions for dangerous contaminants treatment;

5. opportunity to treat as bulk commodity (e.g., no separation or special care is required); 
6. economic incentives and regulatory obligations for collection and recycling (e.g., stewardship programs such as the Extended Producer Responsibility policy [22]);

7. environmental and educational campaigns to raise consumer awareness;

8. promoting recycling supply chain networking and collaboration.

Overall, to achieve positive environmental and economic outcomes, the main criteria for establishing a viable business case for metal recycling in Australia should include:

1. high recovery rates for all major constituents/materials;

2. scalability (to be able to cover growing amounts of EoL products, and their complexity);

3. the potential to achieve the same or better quality of recovered materials (upcycling).

Other important factors to be considered are the total economic value for recovery, presence and removability of hazardous elements, maturity of industry, and consumer behaviour. The full processing of waste materials domestically (versus exporting collected waste for processing overseas) depends on the presence of a market for recovered materials, and competiveness compared with primary production (including imported products).

\section{Conclusions}

The progression towards a circular economy has to undergo significant changes in the main drivers of the current economy: from maximising of economic value and preferred simple technology, to strengthening of environmental regulation, rising of public awareness about environmental impacts and emphasizing the crucial importance of business reputation. In addition, there needs to be a greater focus on designing products with minimal ecological footprint over the product life cycle, and ensuring the supply of secondary resources in a closed loop economy. Other contributing factors include national targets (as set in environmental legislation), regulation and policies (for different actors in the resource supply chain and recycling), producer responsibility (e.g., product stewardship), existing recycling infrastructure and technology, consumer behaviour, information availability (to allow for making rational decisions), and finally actual recycling rates for the overall waste material recovery in the economy.

Domestic application for recovered metals in Australia is still lacking, and limits the closing of material loops. To uncover the opportunities for circular use of resources, new innovations and incentives at different stages in the recycling supply chain are needed. The typology of options presented in this article assists in identifying these opportunities, coupled with the classification of main recycling strategies for different EoL products and emphasizing the potential for creating higher economic value in progressing upstream through the recycling value chain. Specifically, this approach is aimed at targeting complex and Australian EoL consumer products that are currently problematic for recycling. This work will form the basis for producing a maturity model in the subsequent research to provide a further contribution for increasing metals recycling levels. Finally, Australia's knowledge and expertise from extracting, recovering and producing metals from primary sources should be utilized and adapted to develop the necessary innovative technologies and approaches that will help overcome the current barriers to metals recycling and contribute to the evolution towards a circular economy.

Acknowledgments: The authors would like to acknowledge the support of the Wealth from Waste Research Cluster, a collaborative program between the Australian CSIRO (Commonwealth Scientific Industrial Research Organisation), University of Technology Sydney, The University of Queensland, Swinburne University of Technology, Monash University and Yale University.

Author Contributions: Artem Golev led the development of the concepts and outcomes presented in this article and led the writing of this article. Glen Corder contributed to and reviewed the presented concepts and outcomes as well as providing additional writing of the article.

Conflicts of Interest: The authors declare no conflict of interest. 


\section{References}

1. BREE. Resources and Energy Statistics 2013; Bureau of Resources and Energy Economics (BREE): Canberra, Australia, 2013.

2. Corder, G.D.; Golev, A.; Giurco, D. “Wealth from metal waste”: Translating global knowledge on industrial ecology to metals recycling in australia. Miner. Eng. 2015, 76, 2-9. [CrossRef]

3. Golev, A.; Corder, G. Modelling metal flows in the Australian economy. J. Clean. Product. 2016, 112, $4296-4303$. [CrossRef]

4. Golev, A.; Corder, G.D. Global Systems for Industrial Ecology and Recycling of Metals in Australia: Research Report; Prepared for Wealth from Waste Cluster, by the Centre for Social Responsibility in Mining, Sustainable Minerals Institute, The University of Queensland: Brisbane, Australia. Available online: http://wealthfromwaste.net/wp-content/uploads/2014/11/WfW_IE_Global_Systems_Report-2014.pdf (accessed on 31 May 2014).

5. Rajaratnam, T.; Lamb, G. Waste Classifications in Australia: A Comparison of Waste Classifications in the Australian Waste Database with Current Jurisdictional Classifications; Department of Sustainability, Environment, Water, Population and Communities: Sydney, Australia, 2011.

6. UNEP. Metal Recycling: Opportunities, Limits, Infrastructure; A Report of the Working Group on the Global Metal Flows to the International Resource Panel; Reuter, M.A., Hudson, C., van Schaik, A., Heiskanen, K., Meskers, C., Hagelüken, C., Eds.; United Nations Environment Programme (UNEP): Paris, France, 2013.

7. Baldé, C.P.; Wang, F.; Kuehr, R.; Huisman, J. The Global e-Waste Monitor-2014; United Nations University, IAS-SCYCLE: Bonn, Germany, 2015.

8. Randell, P.; Pickin, J.; Grant, B. Waste Generation and Resource Recovery in Australia; Blue Environment Pty Ltd.; Department of Sustainability, Environment, Water, Population and Communities. Available online: http:/ / www.environment.gov.au/resource/waste-generation-and-resource-recovery-australia-report-anddata-workbooks (accessed on 30 June 2014).

9. O’Brien, M.; Miedzinski, M.; Giljum, S.; Doranova, A. Eco-Innovation and Competitiveness: Enabling the Transition to a Resource-efficient Circular Economy; Annual Report 2013; European Commission: Luxembourg, 2014.

10. Brulliard, C.; Cain, R.; Do, D.; Dornom, T.; Evans, K.; Lim, B.; Olesson, E.; Young, S. The Australian Recycling Sector; Net Balance; Department of Sustainability, Environment, Water, Population and Communities: Canberra, Australia, 2012.

11. EEA. Earnings, Jobs and Innovation: The Role of Recycling in a Green Economy; EEA Report No. 8/2011; European Environment Agency (EEA): Copenhagen, Denmark, 2011.

12. WEF. Towards the Circular Economy: Accelerating the Scale-up Across Global Supply Chains; Prepared in collaboration with the Ellen MacArthur Foundation and McKinsey \& Company; World Economic Forum (WEF): Geneva, Switzerland; Available online: http:/ / reports.weforum.org/toward-the-circulareconomy-accelerating-the-scale-up-across-global-supply-chains (accessed on 30 June 2014).

13. Allwood, J.M. Chapter 30-Squaring the circular economy: The role of recycling within a hierarchy of material management strategies. In Handbook of Recycling; Worrell, E., Reuter, M.A., Eds.; Elsevier: Boston, UK, 2014; pp. 445-477.

14. Yamashita, H.; Kishino, H.; Hanyu, K.; Hayashi, C.; Abe, K. Circulation indices: New tools for analyzing the structure of material cascades. Resour. Conserv. Recycl. 2000, 28, 85-104. [CrossRef]

15. Sirkin, T.; Houten, M.T. The cascade chain: A theory and tool for achieving resource sustainability with applications for product design. Resour. Conserv. Recycl. 1994, 10, 213-276. [CrossRef]

16. Corder, G.D.; Golev, A.; Fyfe, J.; King, S. The status of industrial ecology in australia: Barriers and enablers. Resources 2014, 3, 340-361. [CrossRef]

17. Khaliq, A.; Rhamdhani, M.; Brooks, G.; Masood, S. Metal extraction processes for electronic waste and existing industrial routes: A review and australian perspective. Resources 2014, 3, 152-179. [CrossRef]

18. Corder, G.D.; Golev, A. Industrial Ecology Forum "Shifting the Australian Resources Paradigm"; Outcomes and Findings Report; Prepared for Wealth from Waste Cluster, by the Centre for Social Responsibility in Mining, Sustainable Minerals Institute; The University of Queensland: Brisbane, Australia; 28 March 2014; Sydney, Australia, 2014. 
19. Corder, G.D.; Golev, A. Second Industrial Ecology Workshop "Shifting the Australian Resources Paradigm"; Outcomes and Findings Report; Prepared for Wealth from Waste Cluster, by the Centre for Social Responsibility in Mining, Sustainable Minerals Institute; The University of Queensland: Brisbane, Australia; Available online: http://wealthfromwaste.net/wp-content/uploads/2014/11/WfW-Workshop2-Report-Dec-2014.pdf (accessed on 23 December 2014).

20. Gumley, W. An analysis of regulatory strategies for recycling and re-use of metals in australia. Resources 2014, 3, 395-415. [CrossRef]

21. Lane, R. Understanding the dynamic character of value in recycling metals from australia. Resources 2014, 3, 416-431. [CrossRef]

22. OECD. Extended Producer Responsibility: A guidance Manual for Governments; Organisation for Economic Cooperation and Development (OECD): Paris, France, 2001.

(C) 2015 by the authors; licensee MDPI, Basel, Switzerland. This article is an open access article distributed under the terms and conditions of the Creative Commons by Attribution (CC-BY) license (http://creativecommons.org/licenses/by/4.0/). 